\title{
Cigarette smoking and benign breast disease*
}

\author{
GERTRUD S BERKOWITZ, ${ }^{1}$ PRISCILLA F CANNY, ${ }^{2}$ VIRGINIA A VIVOLSI, ${ }^{3}$ \\ MARIA J MERINO, ${ }^{4}$ THERESA Z O'CONNOR, ${ }^{2}$ AND JENNIFER L KELSEY ${ }^{5}$
}

From the Departments of Obstetrics, Gynaecology and Reproductive Science, and Community Medicine, ${ }^{1}$ Mount Sinai Medical Center, New York, NY, 10029; Department of Epidemiology and Public Health, ${ }^{2}$ Yale University School of Medicine, New Haven, CT, 06510; Department of Pathology and Laboratory Medicine, ${ }^{3}$ University of Pennsylvania School of Medicine, Philadelphia, PA, 19104; Department of Pathology, ${ }^{4}$ Yale University School of Medicine, New Haven, CT, 06510; Division of Epidemiology, ${ }^{5}$ Columbia University School of Public Health, New York, NY, 10032, USA

SUMMARY The association between cigarette smoking and the occurrence of benign breast disease was assessed in a hospital-based case-control study conducted in Connecticut during 1979-81. Current smokers, but not former smokers, were at reduced risk for all benign breast diseases. The odds ratios associated with current smoking were $0.7(95 \%$ confidence intervals $=0.6,0.9)$ for fibrocystic breast disease, $0.6(95 \%$ confidence intervals $=0.5,0.9)$ for fibroadenoma, $0.6(95 \%$ confidence intervals $=0.4,1.0)$ for fibrocystic breast disease concomitant with fibroadenoma, and $0.6(95 \%$ confidenc度 intervals $=0.5,0.9$ ) for other benign breast disease. Adjustments for potentially confounding variables, including indices of medical care utilisation, affected these odds ratios only slightly. There was no convincing evidence of an association, either negative or positive, between current cigarette smoking an the degree of epithelial atypia of the fibrocystic lesions. However, the negative association between fibrocystic disease and current cigarette smoking was strongest for atypical lobular hyperplasia, which in turn has been associated with a particularly elevated risk of subsequent breast cancer.

A recent review $^{1}$ of the relation between cigarette smoking and oestrogen-related disease has indicated that smoking may have an anti-oestrogenic effect and that the risk of oestrogen-related diseases may be altered among female smokers. Since there is at least indirect evidence that benign breast disease is hormonally related, the effect of cigarette smoking was assessed in a hospital-based case-control study of fibrocystic breast disease and fibroadenoma.

\section{Methods}

The data were drawn from a study which had the primary purpose of assessing the association between exogenous hormone use and fibrocystic breast disease according to histopathological components. Details of this study have been presented previously. ${ }^{2-4} \mathrm{~A}$ related study of the epidemiology of fibroadenoma ${ }^{5}$ was conducted within the framework of this investigation.

Potential cases of benign breast diseases were women aged 20-74 years identified from the pathology records of five Connecticut hospitals during the period November 1979 to November 1981. Since fibroadenoma has a younger age distribution than fibrocystic breast disease, ${ }^{6,7}$ the age limit was lowered to 18 years for the fibroadenoma cases. All biopsy slides were reviewed b one pathologist associated with the study (VAL), and a sample of slides was evaluated by a second pathologist (MJM). Neither pathologist had any knowledge of the patient's medical history or exposure to potential risk factors. The study definition of fibrocystic breast disease was the presence of microcysts or gross cysts. ${ }^{8}$ Of 1232 potential fibrocystic breast disease and fibroadenoma cases, the study pathologist classified 634 as having fibrocystic breast disease, 251 as having fibroadenoma, and 74 as having fibrocystic breast disease concomitant with fibroadenoma. The remaining 273 women were classified as having other benign breast conditions as their biopsy slides exhibited insufficient evidence of microcysts, gross cysts, or fibroadenomas according to the study pathologists. The most common histological elements in this group were fibrosis $(50.2 \%)$ and adenosis $(46.2 \%)$.

The histology of the fibrocystic lesions was evaluated according to the systems of Black and Chabon ${ }^{9}$ and Haagensen. ${ }^{10}$ In the Black and Chabon classification, the degree of atypia in each of the four groups of breast ducts

* Supported by PHS Grant No. 5 RO1 CA-26021 awarded by the National Cance Institute, DHHS 
is graded from 1 (normal) to 5 (extreme disorganisation with malignant changes). No biopsy specimens with grade 5 were included in the study. An average of the four duct grades was used to assess overall degree of atypia. The Haagensen categorisation considers the presence or absence of individual histological elements, such as microcysts, gross cysts, apocrine metaplasia, adenosis and sclerosing adenosis, papillomatosis, papillary hyperplasia, and lobular neoplasia.

Controls were sampled from the inpatient and outpatient general surgical services of the same hospitals during the same time period as the cases. No more than $10 \%$ of the controls were from any single diagnostic category. Apart from the addition of controls in the 18-19 year age group for the analysis involving the fibroadenoma cases, the same control group was used for both the fibrocystic and the fibroadenoma cases. Controls were group-matched to the benign breast disease cases by 10-year age intervals in an approximately 1:1 ratio. However, discrepancies in the age distribution are apparent when the controls are compared to each of the four benign breast disease groups separately (table 1).

Women with the following admitting diagnoses were not eligible for the control series: cancer of the breast or of a reproductive organ, thrombophlebitis, varicose veins, gallbladder disease, and breast abscess. Excluded from consideration either as a case or control were women with a history of cancer of the breast or of a reproductive site, women who did not speak English, out-of-state residents, and women who lived in areas designated as unsafe for home interviews. In addition, one case and four controls who had experienced no or only an occasional menstrual period during their reproductive years were excluded from the analysis. In the analysis, 633 fibrocystic breast disease cases were compared with 1062 controls and 251 fibroadenoma cases with 1077 controls. Participation rates were $80 \%$ for the eligible patients with benign breast diseases and $75 \%$ for the eligible controls.

A standardised structured questionnaire administered by trained interviewers included information on demographic characteristics, medical, surgical, menstrual, and reproductive histories, exogenous hormone exposure, and use of cigarettes, alcohol, and caffeine. The women were classified as non-smokers, ex-smokers (at least one cigarette a day for three or more months but not during the year before the interview), and current smokers (at least one cigarette a day for three or more months during the year before the interview).

Linear logistic regression models ${ }^{11}$ were used to test for the effects of the following potential confounders and effect modifiers: age, marital status, socioeconomic status, ${ }^{12}$ race, religion, father's birthplace, Quetelet's index, age at menarche, nulliparity, age at first pregnancy or live birth, age at menopause, type of menopause, recent history of annual medical check-ups and annual breast exams, practice of breast self-examination, history of benign breast disease, history of medical complications, family history of breast cancer, history of tubal sterilisation, exogenous hormone use, and caffeine use. The odds ratio is used as the measure of association in this report.

\section{Results}

Table 2 presents the distribution of smoking habits for the fibrocystic and fibroadenoma cases and their respective controls. With women who had never smoked serving as the referent group, a decreased odds ratio of fibrocystic breast disease was evident for current smokers (odds ratio $=0.7,95 \%$ confidence intervals $0.6,0.9$ ) but not ex-smokers (odds ratio $=1.1,95 \%$ confidence intervals $0.8,1.4$ ). Adjustment for age and Quetelet's index (table 2) as well as other potentially confounding variables affected these odds ratios only slightly. As a result, unadjusted odds ratios of fibrocystic breast disease will be presented unless otherwise specified.

The odds ratios of fibroadenoma and fibrocystic disease with concomitant fibroadenoma were below 1.0 for both ex and current smokers. However, when the effects of age and Quetelet's index were taken into account, the reduction in the adjusted odds ratios was only statistically significant for the current smokers. Adjustment for other potential confounders did not materially change these results.

Table 1 Age distribution of women with fibrocystic breast disease, fibroadenoma, fibrocystic breast disease with concomitant fibroadenoma, other benign brease disease, and controls, five Connecticut hospitals, 1979-81

\begin{tabular}{|c|c|c|c|c|c|c|c|c|c|c|}
\hline \multirow[t]{2}{*}{ Age (yr) } & \multicolumn{2}{|c|}{$\begin{array}{l}\text { Fibrocystic } \\
\text { breast disease }\end{array}$} & \multicolumn{2}{|c|}{ Fibroadenoma } & \multicolumn{2}{|c|}{$\begin{array}{l}\text { Fibrocystic with } \\
\text { fibroadenoma }\end{array}$} & \multicolumn{2}{|c|}{$\begin{array}{l}\text { Other benign } \\
\text { breast disease }\end{array}$} & \multicolumn{2}{|c|}{ Controls* } \\
\hline & No. & $\%$ & No. & $\%$ & No. & $\%$ & No. & $\%$ & No. & (\%) \\
\hline $18-19$ & 0 & 0.0 & 35 & 13.9 & 0 & 0.0 & 0 & 0.0 & 15 & 1.4 \\
\hline $20-29$ & 47 & 7.4 & 105 & 41.8 & 7 & 9.5 & 55 & 20.2 & 174 & 16.2 \\
\hline $30-39$ & 163 & 25.8 & 62 & 24.7 & 23 & 31.1 & 89 & 32.6 & 293 & 27.2 \\
\hline $40-49$ & 238 & 37.6 & 31 & 12.4 & 31 & 41.9 & 51 & 18.7 & 273 & 25.3 \\
\hline $50-59$ & 120 & 19.0 & 8 & 3.2 & 11 & 14.9 & 45 & 16.5 & 184 & 17.1 \\
\hline $60-69$ & 56 & 8.8 & 8 & 3.2 & 2 & 2.7 & 26 & 9.5 & 113 & 10.5 \\
\hline $70-74$ & 9 & 1.4 & 2 & 0.8 & 0 & 0.0 & 7 & 2.6 & 25 & 2.3 \\
\hline Total & 633 & & 251 & & 74 & & 273 & & 1077 & \\
\hline
\end{tabular}

* Controls aged 18-19 years were included only in the analysis of fibroadenoma cases. 
Table 2 Distribution of cigarette smoking habits among women with fibrocystic disease, fibroadenoma, fibrocystic disease with concomitant fibroadenoma and controls, associated odds ratios and 95\% confidence intervals, five Connecticut hospitals, $1979-81$

\begin{tabular}{|c|c|c|c|c|c|c|c|c|c|c|}
\hline $\begin{array}{l}\text { Smoking } \\
\text { status }\end{array}$ & $\begin{array}{l}\text { Controls* } \\
\text { (No.) }\end{array}$ & $\begin{array}{l}\text { Fibrocystic } \\
\text { disease } \\
\text { cases } \\
\text { (No.) }\end{array}$ & $\begin{array}{l}\text { Unadjusted } \\
\text { odds ratio } \\
\text { ( } 95 \% \\
\text { confidence } \\
\text { intervals) }\end{array}$ & $\begin{array}{l}\text { Adjusted } \dagger \\
\text { odds ratio } \\
(95 \% \\
\text { confidence } \\
\text { intervals) }\end{array}$ & $\begin{array}{l}\text { Fibroadenoma } \\
\text { cases } \\
\text { (No.) }\end{array}$ & $\begin{array}{l}\text { Unadjusted } \\
\text { odds ratio } \\
\text { (95\% } \\
\text { confidence } \\
\text { intervals) }\end{array}$ & $\begin{array}{l}\text { Adjusted } \dagger \\
\text { odds ratio } \\
\text { (95\% } \\
\text { confidence } \\
\text { intervals) }\end{array}$ & $\begin{array}{l}\text { Fibrocystic } \\
\text { disease } \\
\text { with } \\
\text { fibroadenoma } \\
\text { cases } \\
\text { (No.) }\end{array}$ & $\begin{array}{l}\text { Unadjusted } \\
\text { odds ratio } \\
\text { ( } 95 \% \\
\text { confidence } \\
\text { intervals) }\end{array}$ & $\begin{array}{l}\text { Adjusted } \dagger \\
\text { odds ratio } \\
\text { (95\% } \\
\text { confidence } \\
\text { intervals) }\end{array}$ \\
\hline Never $\ddagger$ & 365 & 249 & 1.0 & 1.0 & 116 & 1.0 & 1.0 & 33 & 1.0 & 1.0 \\
\hline Ex-smoker & 222 & 163 & $\begin{array}{c}1.1 \\
(0.8-1.4)\end{array}$ & $\begin{array}{c}1.0 \\
(0.8-1.3)\end{array}$ & 38 & $\begin{array}{c}0.5 \\
(0.4-0.8)\end{array}$ & $\begin{array}{c}0.7 \\
(0.6-1.2)\end{array}$ & 16 & $\begin{array}{c}0.8 \\
(0.4-1.5)\end{array}$ & $\begin{array}{c}0.8 \\
(0.4-1.5)\end{array}$ \\
\hline Current smoker & 458 & 217 & $\begin{array}{c}0.7 \\
(0.6-0.9)\end{array}$ & $\begin{array}{c}0.6 \\
(0.5-0.8)\end{array}$ & 94 & $\begin{array}{c}0.6 \\
(0.5-0.9)\end{array}$ & $\begin{array}{c}0.7 \\
(0.5-0.9)\end{array}$ & 25 & $\begin{array}{c}0.6 \\
(0.4-1.0)\end{array}$ & $\begin{array}{c}0.6 \\
(0.3-0.96)\end{array}$ \\
\hline Not recorded & 17 & 4 & & & 3 & & & 0 & & \\
\hline Total & 1062 & 633 & & & 251 & & & 74 & & \\
\hline
\end{tabular}

* The smoking distribution of the 1077 controls used in the comparison with the fibroadenoma cases was as follows: 372 never smoked, 222 ex-smokers, 466 current smokers, and 17 not recorded.

$\uparrow$ Adjusted for age and Quetelet's index.

$\ddagger$ Referent group.

To assess whether the negative associations with current smoking reflect the presence of smoking-related disorders among the controls, the fibrocystic and fibroadenoma cases were compared to a subgroup of controls whose admission diagnosis indicated an acute surgical condition or a condition regarded as unlikely to be associated with cigarette smoking (eg, appendicitis, hernia, haemorrhoids). Limiting the analysis to this subgroup, however, did not alter these associations. The cases and controls were also stratified by type of patient (inpatient $v$ outpatient). Although the odds of fibrocystic disease for current smokers was lower among the inpatients than the outpatients, and the opposite was true for the odds of fibroadenoma, there were no significant interactions among type of patient, smoking status, and the odds of either fibrocystic disease or fibroadenoma. Similarly, excluding cases with a history of benign breast disease affected the results only slightly.

When the fibrocystic cases and controls were stratified by menopausal status, ${ }^{2}$ the reduction in the unadjusted odds ratio for current smokers was more marked among the postmenopausal than the premenopausal women (table 3). Multivariable analysis had no effect on the odds ratios among the premenopausal women but further reduced the odds ratios among the postmenopausal women from 0.9 to 0.6 (95\% confidence intervals $=0.3$, 1.2) for the ex-smokers and from 0.5 to $0.4(95 \%$ confidence intervals $=0.2,0.8$ ) for the current smokers. Specifically, the multivariable analysis revealed that adjustments for Quetelet's index, but not such other potential confounders or effect modifiers as age at menopause or use of oestrogen replacement therapy, reduced the odds ratios among the postmenopausal women. Furthermore, the negative association with current cigarette smoking was found to be strongest for the women in the lowest quartile for the Quetelet's index (odds ratio for women with a Quetelet's index $\leqslant 21=0.3$ compared to 0.5 for those with a Quetelet's index $>21$ ). Similar analysis for the fibroadenoma cases was not meaningful since there were only 14 postmenopausal fibroadenoma cases.

Since the degree of epithelial atypia of the fibrocystice lesion has been positively associated with subsequent risk of breast cancer, the association between cigarette smoking and degree of epithelial atypia among the fibrocystic cases was assessed. With the controls serving? as the referent group, there was no convincing evidence of a linear trend with extent of epithelial atypia among either the ex or the current smokers (table 4).

The association between smoking status and selected Haagensen characteristics of the fibrocystic cases is presented in table 5. Cases with biopsy specimens exhibiting atypical lobular hyperplasia and, to a lesser extent, papillomatosis appeared to be the least likely to be current smokers. With the exception of these histological elements, there was little variation in the association with individual Haagensen components among either the ex or the current smokers.

To evaluate whether the negative association with current smoking was specific to fibrocystic disease and

Table 3 Odds ratios and 95\% confidence intervals for association between cigarette smoking and fibrocystic breast disease by menopausal status, five Connecticut hospitals, 1979-81

\begin{tabular}{|c|c|c|c|c|}
\hline \multirow{2}{*}{$\begin{array}{l}\text { Smoking } \\
\text { status }\end{array}$} & \multicolumn{2}{|c|}{ Premenopausal women } & \multicolumn{2}{|c|}{ Postmenopausal women } \\
\hline & Odds ratio & $95 \%$ confidence intervals & Odds ratio & $95 \%$ confidence intervals \\
\hline Never* & 1.0 & - & 1.0 & - \\
\hline $\begin{array}{l}\text { Ex-smoker } \\
\text { Current }\end{array}$ & $\begin{array}{l}1.2 \\
0.8\end{array}$ & $\begin{array}{l}0.9-1.7 \\
0.6-1.0\end{array}$ & $\begin{array}{l}0.9 \\
0.5\end{array}$ & $\begin{array}{l}0.5-1.5 \\
0.3-0.8\end{array}$ \\
\hline
\end{tabular}

* Referent group 
Table 4 Odds ratios* for association between cigarette smoking and fibrocystic disease by degree of epithelial atypia, and tests for linear trends, five Connecticut hospitals, 1979-81

\begin{tabular}{|c|c|c|}
\hline $\begin{array}{l}\text { Mean epithelial } \\
\text { anypia }\end{array}$ & $\begin{array}{l}\text { Ex } \\
\text { smokers }\end{array}$ & $\begin{array}{l}\text { Current } \\
\text { smokers }\end{array}$ \\
\hline $\begin{array}{l}1.00-1.29 \\
1.30-1.79 \\
1.80-2.29 \\
2.30-3.00\end{array}$ & $\begin{array}{l}1.1(96) \dagger \\
1.1(47) \\
0.6(11) \\
1.9(7)\end{array}$ & 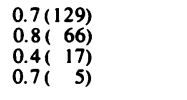 \\
\hline Test for linear trend $\ddagger$ & $\chi_{1}^{2}=0.38, p=0.54$ & $x_{1}^{2}=1.21, p=0.27$ \\
\hline
\end{tabular}

* The controls served as the referent group in calculating the odds ratios.

$\dagger$ Number of cases given in parentheses.

$\ddagger$ The controls were not included in the tests for linear trend.

Table 5 Odds ratios and $95 \%$ confidence intervals for association between smoking status and fibrocystic breast disease for cases with selected Haagensen characteristics compared to controls, five Connecticut hospitals, 1979_81

\begin{tabular}{|c|c|c|c|c|}
\hline \multirow{2}{*}{$\begin{array}{l}\text { Haagensen } \\
\text { characteristic }\end{array}$} & \multicolumn{2}{|l|}{ Ex-smokers } & \multicolumn{2}{|c|}{ Current smokers } \\
\hline & Odds ratio & $95 \%$ confidence intervals & Odds ratio & $95 \%$ confidence intervals \\
\hline $\begin{array}{l}\text { Microycysts (599)* } \\
\text { Apocrine metaplasia (585) } \\
\text { Gross cysts (463) } \\
\text { Papillary hyperplasia (263) } \\
\text { Papillomatosis (245) } \\
\text { Sclerosing adenosis (230) } \\
\text { Atypical lobular hyperplasia (26) }\end{array}$ & $\begin{array}{l}1.1 \\
1.0 \\
1.0 \\
1.1 \\
1.2 \\
1.0 \\
0.8\end{array}$ & $\begin{array}{l}0.8-1.4 \\
0.8-1.4 \\
0.7-1.3 \\
0.8-1.6 \\
0.8-1.7 \\
0.7-1.5 \\
0.3-2.0\end{array}$ & $\begin{array}{l}0.7 \\
0.7 \\
0.7 \\
0.7 \\
0.6 \\
0.8 \\
0.3\end{array}$ & $\begin{array}{l}0.6-0.9 \\
0.5-0.9 \\
0.5-0.9 \\
0.5-1.0(0.95) \\
0.4-0.9 \\
0.5-1.1 \\
0.1-0.8\end{array}$ \\
\hline
\end{tabular}

- The number of cases with the specific characteristics is given in parentheses. The categories are not mutually exclusive.

fibroadenoma, the smoking status of the women with other benign breast disease (that is, the 273 women whose biopsy specimens exhibited insufficient evidence of cystic changes or the presence of fibroadenoma) was compared to that of the controls. The unadjusted odds ratio for the women with other benign breast disease was $0.9(95 \%$ confidence intervals $=0.7,1.3)$ for ex-smokers and $0.6(95 \%$ confidence intervals $=0.5,0.9)$ for current smokers. Adjustment for age and Quetelet's index did not change these odds ratios.

\section{Discussion}

Our data suggest that current cigarette smoking is negatively associated with the occurrence of benign breast diseases, while past smoking is generally unrelated to the likelihood of disease. This suggests that the influence of smoking on the occurrence of benign breast disease is reversible after the end of exposure.

There is growing evidence that cigarette smoking may affect oestrogen-related processes and disorders. It is well documented that smokers have an earlier natural menopause than nonsmokers. ${ }^{1,13-15}$ MacMahon and colleagues ${ }^{16}$ have also reported that urinary oestrogen levels in luteal specimens were lower in current smokers than in ex-smokers or nonsmokers. Female smokers may have lower bone mass, ${ }^{1,17,18}$ and may be more likely to suffer from osteoporotic fractures, ${ }^{1,17,19}$ than nonsmokers. With respect to other oestrogen-related diseases, there is some evidence that smoking is negatively associated with endometrial cancer, ${ }^{1,20-22}$ and that this effect is independent of the association between smoking and age at natural menopause. Although it has been suggested that smokers may be at a reduced risk for breast cancer, ${ }^{16}$ the epidemiological literature has provided conflicting results. ${ }^{1,22-28}$ However, while endometrial cancer has been firmly linked with at least exogenous oestrogens, ${ }^{21,22-20}$ there is little, if any, evidence for a similar association with breast cancer. ${ }^{23,30,31}$

Several mechanisms ${ }^{1,15}$ have been considered for the apparent anti-oestrogenic impact of smoking, including a direct toxic effect on the ovaries, which would in turn accelerate the onset of menopause; an interference with oxidative systems which affect peripheral oestrogen metabolism; and a reduction in the amount of adipose tissue available for conversion of androgens to oestrogens, a process that would be mediated by the tendency of smokers to be leaner than nonsmokers.

Although the controls had an earlier age at menopause than the fibrocystic cases in our study, the inverse association between fibrocystic disease and current cigarette smoking was independent of the effect of age at menopause. Menopausal status did, however, influence our results in that the smoking effect was stronger among the postmenopausal than the premenopausal women. A similar finding has been observed in one of the studies that reported a decreased risk of breast cancer for current smokers. ${ }^{1,25}$ Since adjustment for Quetelet's index did not affect the results for the premenopausal women and actually strengthened the results for the postmenopausal women, differences in body weight for height between 
smokers and nonsmokers do not explain the negative association between current cigarette smoking and the odds of fibrocystic disease. Furthermore, among postmenopausal women, the negative association was strongest for the women in the lowest quartile for the Quetelet's index. This finding suggests that among postmenopausal women the smoking effect may be most pronounced among those who already have a reduced potential for extra-ovarian production of oestrogens.

A negative association between current cigarette smoking and benign breast disease has not been noted in the literature previously. Nomura and Comstock ${ }^{32}$ reported that cystic cases were more likely to have had a positive smoking history and the fibroadenoma cases were less likely to have smoked than age-matched controls. No information, however, was collected on current cigarette smoking. Furthermore, this study used population-based controls, which may not be an appropriate control group when studying a disorder such as benign breast disease, which does not necessarily come to medical attention.

Although the aetiology of benign breast disease is not well established, evidence from both animal and human studies is suggestive of a hormonal role in the pathophysiology of benign breast disease. Exogenous oestrogen administration has been linked with benign mammary lesions in animal experiments. ${ }^{33 \cdot 35}$ A positive association between oestrogen replacement therapy and the occurrence of fibrocystic breast disease among postmenopausal women was observed in the present investigation, ${ }^{4}$ as well as in others. ${ }^{36,37} \mathrm{~A}$ similar association was also noted for the fibroadenoma cases over the age of 45 in this study. ${ }^{5}$ Furthermore, a few investigators have found abnormally high oestrogen levels ${ }^{38}$ or an imbalance between oestrogen and progesterone levels ${ }^{39}$ among women with benign breast disease.

The analysis of mean ductal atypia provided no convincing evidence of a negative association between current smoking and extent of epithelial atypia of the fibrocystic lesion. The elevated odds ratio in the highest atypia group for ex-smokers is of interest since some investigators ${ }^{1,24}$ have found higher rates of breast cancer among ex-smokers compared to current smokers or those who have never smoked. The strong negative association between current cigarette use and atypical lobular neoplasia is noteworthy as this rare type of fibrocystic lesion has been associated with a particularly elevated risk of breast cancer ${ }^{40,41}$ Current smoking was also associated with a substantial reduction in the odds ratio for papillomatosis, which has been found to have an increased malignant potential as well. ${ }^{40,42}$ Thus, there is some suggestion, on the basis of the analysis of the Haagensen elements, that the negative association with cigarette smoking may be most apparent at least for selected fibrocystic lesions suspected of being associated with a subsequently elevated breast cancer risk.

Although adjustment for potentially confounding variables, including measures of medical care utilisation, did not appear to alter our overall results, it is still possible that the women with benign breast diseases differed from $T$ the controls in terms of health consciousness or other $\stackrel{D}{\mathbb{D}}$ unidentified characteristics that may be responsible for our findings. It is known ${ }^{43}$ that hospitalised patients tend to have higher smoking rates than the general population, $\stackrel{9}{+}$ but both the cases and the controls in this investigation were drawn from surgical services. Further, the negative 흘 association with current smoking was observed both for $\frac{\bar{c}}{\vec{D}}$

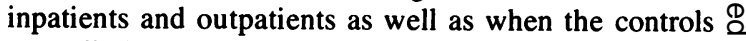
were limited to those with acute surgical conditions. \& Nevertheless, because we cannot rule out the possibility $\vec{\circ}$ that the choice of controls in this study may have biased. our results, the finding that current cigarette smoking is $\vec{\omega}$ associated with a reduction in the occurrence of all benign breast diseases is clearly preliminary.

Since the questionnaire was focused on exogenot hormone use, and since smoking was thought to b8 unrelated to the occurrence of fibrocystic disease at the time the investigation was undertaken, no information was obtained on duration of smoking or quantity cigarette use. Further studies are therefore needed nळ only to confirm or refute our results but also to determine whether there is a dose-response relation.

If cigarette smoking reduces endogenous oestroged levels, this anti-oestrogenic effect may be translated into reduced risk of fibrocystic as well as other benign breas diseases. While such a potential benefit can hard $\overrightarrow{0}$ outweigh the more serious health risks associated with or smoking, it is nevertheless of interest because it may shed light on aetiological mechanisms.

We thank the physicians, staff, and patients of Yale-New Haven Hospital, Hospital of St Raphael, Waterbury Hospital, Hartford Hospital, and St Vincent's Medical Center. We are grateful to Ms Carol Shiroky for assistance with the manuscript.

Address reprint requests to Dr Berkowitz, Department of Obstetrics, Gynaecology and Reproductive Science, Mount Sinai Medical Center, 1 Gustave L Levy Place, New York, NY, 10029, USA.

\section{References}

'Baron JA. Smoking and oestrogen-related disease. Am J Epidemiol 1984; 119: 9-22.

${ }^{2}$ Berkowitz GS, Kelsey JL, LiVolsi VA, et al. Oral contraceptive use and fibrocystic breast disease among pre and $N$ postmenopausal women. Am J Epidemiol 1984; 120: 87-96. ๙

${ }^{3}$ Berkowitz GS, Kelsey JL, LiVolsi VA, et al. Exogenous N hormone use and fibrocystic breast disease by histopathologic component. Int J Cancer 1984; 34: 443-9. 
${ }^{4}$ Berkowitz GS, Kelsey JL, Holford TR, et al. Oestrogen replacement therapy and fibrocystic breast disease in postmenopausal women. Am J Epidemiol 1985; 121: $238-45$.

${ }^{5}$ Canny PF. The epidemiology of fibroadenoma. PhD dissertation, New Haven: Yale University, 1983.

${ }^{6}$ Cole P, Elwood JM, Kaplan SD. Incidence rates and risk factors of breast neoplasms. Am J Epidemiol 1978; 108: 112-210.

${ }^{7}$ Haagensen CD. Diseases of the breast. Second edition. Philadelphia: WB Saunders, 1971.

${ }^{8}$ LiVolsi VA, Stadel BV, Kelsey JL, Holford TR, White C. Fibrocystic breast disease in oral-contraceptive users: a histopathological evaluation of epithelial atypia. N Engl J Med 1978; 299: 381-5.

${ }^{9}$ Black MM, Chabon AB. In situ carcinoma of the breast. Path Ann 1969; 4: 185-210.

${ }^{10}$ Haagensen $C D$. The relationship of gross cystic disease of the breast and carcinoma. Ann Surg 1977; 185: 375-6.

${ }^{11}$ Breslow NE, Day NE. Statistical methods in cancer research. Vol I, Lyon, France: IARC, 1980.

${ }^{12}$ Hollingshead AB. Two-factor index of social position. New Haven, CT: Hollingshead Publications, 1957.

${ }^{13}$ Kaufman DW, Slone D, Rosenberg L, Miettinen OS, ShapiroS. Cigarette smoking and age at natural menopause. Am JPublic Health 1980; 70: 420-2.

${ }^{14} \mathrm{Jick} H$, Porter J, Morrison AS. Relation between smoking and age of natural menopause. Lancet 1977; 1: 1354-5.

${ }^{15}$ Willett W, Stampfer MJ, Bain C, et al. Cigarette smoking, relative weight, and menopause. Am J Epidemiol 1983; 117: 651-8.

${ }^{17}$ MacMahon B, Trichopoulos D, Cole P, Brown J. Cigarette smoking and urinary oestrogens. N Engl J Med 1982; 307: 1062-5.

${ }^{17}$ Daniell HW. Osteoporosis of the slender smoker. Arch Intern Med 1976; 136: 298-304.

${ }^{18}$ Lindsay $R$. The influence of cigarette smoking on bone mass and bone loss. In: DeLuca HF, Frost HM, Jee WSS, Johnston CC, Parfitt AM, eds. Osteoporosis: recent advances in pathogenesis and treatment. Baltimore, University Park Press, 1981;481.

${ }^{19}$ Williams AR, Weiss NS, Ure CL, Ballard J, Daling JR. Effect of weight, smoking, and oestrogen use on the risk of hip and forearm fractures in postmenopausal women. Obstet Gynecol 1982; 60: 694-9.

${ }^{20}$ Weiss NS, Farewell VT, Szekely DR, English DR, Kiviat N. Oestrogens and endometrial cancer: effect of other risk factors on the association. Maturitas 1980; 2: 185-90.

${ }^{21}$ Kelsey JL, LiVolsi VA, Holford TR, et al. A case-control study of cancer of the endometrium. Am J Epidemiol 1982; 116: 33-42.

${ }^{22}$ Williams RR, Horm JW. Association of cancer sites with tobacco and alcohol consumption and socioeconomic status of patients: interview study from the Third National Cancer Survey. JNCI 1977; 58: 525-47.

${ }^{23}$ Kelsey JL, Fischer DB, Holford TR, LiVolsi VA, Mostow ED, Goldenberg IS, White C. Exogenous oestrogens and other factors in the epidemiology of breast cancer. JNCI 1981; 67: 327-33.
${ }^{24}$ Hiatt RA, Friedman GD, Bawol RD, Ury HK. Breast cancer and serum cholesterol. JNCI 1982; 68: 885-9.

${ }^{25}$ Vessey M, Baron J, Doll R, McPherson K, Yeates D. Oral contraceptives and breast cancer. Final report of an epidemiological study. Br J Cancer 1983; 47: 455-62.

${ }^{26}$ Rosenberg L, Schwingl PJ, Kaufman DW, et al. Breast cancer and cigarette smoking. N Engl J Med 1984; 310: 92-4.

${ }^{2}$ Smith DC, Prentice R, Thompson DJ, Herrmann WL. Association of exogenous oestrogen and endometrial carcinoma. NEngl JMed 1975; 293: 1164-7.

${ }^{28}$ Jick H, Watkins RN, Hunter JR, Dinan BJ, Madsen S, Rothman $\mathrm{KJ}$, Walker AM. Replacement oestrogens and endometrial cancer. NEngl J Med 1979; 300: 218-22.

${ }^{20}$ Shapiro S, Kaufman DW, Slone D, et al. Recent and past use of conjugated oestrogens in relation to adenocarcinoma of the endometrium. $N$ Engl JMed 1980; 303: 485-9.

${ }^{30}$ Kaufman DW, Miller DR, Rosenberg L, Helmrich SP, Stolley $P$, Schottenfeld D, Shapiro S. Noncontraceptive oestrogen use and the risk of breast cancer. JAMA 1984; 252: 63-7.

${ }^{31}$ Hulka BS. When is the evidence for "no association" sufficient? (Editorial) JAMA 1984; 252 : 81-2.

${ }^{32}$ Nomura A, Comstock GW, Tonascia JA. Epidemiologic characteristics of benign breast disease. Am J Epidemiol 1977; 105: 505-12.

${ }^{33}$ Heiman J. Comparative effects of oestrogen, testosterone and progesterone on benign mammary tumors of the rat. Cancer Res 1943; 3: 65-9.

${ }^{34}$ Bassler R. The morphology of hormone induced structural changes in the female breast. Curr Topics Pathol 1970; 53: $1-89$.

${ }^{35}$ Yoshida H, Fukunishi R. Effects of sex steriods on the development of 7,12-Dimethylbenz(a) anthracene-induced mammary dysplasia in neonatally androgenized female rats. Gann 1981; 72: 315-7.

${ }^{36}$ Trapido E, Brinton L, Schairer C, Hoover R. Oestrogen replacement therapy and benign breast disease. (Abstract) Am J Epidemiol 1984; 120: 461.

${ }^{37}$ Pastides $\mathrm{H}$. The epidemiology of fibrocystic breast disease with special reference to its histopathology. Doctoral dissertation, Yale University, 1980.

${ }^{38}$ Bertini B, Ber A. The ethnologic and endocrinological aspects of breast cancer and cystic mastopathy in Israel. Cancer 1964; $17: 438-49$.

${ }^{39}$ Sitruk-Ware R, Sterkers N, Mauvais-Jarvis P. Benign breast disease. I. Hormonal investigation. Obstet Gynecol 1979; 53: 457-60.

${ }^{4}$ Page DL, Vander Zwaag R, Rogers LWE, Williams LT, Walker WE, Hartmann WH. Relation between component parts of fibrocystic disease complex and breast cancer. J Natl Cancer Inst 1978; 61: 1055-63.

${ }^{41}$ Dupont WD, Page DL. Risk factors for breast cancer in women with proliferative breast disease. $N$ Engl J Med 1985; 312: 146-51.

${ }^{42}$ Hutchinson WB, Thomas DB, Hamlin WB, Roth GJ, Peterson AV, Williams B. Risk of breast cancer in women with benign breast disease. J Natl Cancer Inst 1980; 65: 13-20.

${ }^{4}$ Schlesselmann JJ. Case-control studies. New York: Oxford University Press, 1983; 134. 